Editorial

\title{
Toxicology of the Drug Cypervit
}

\author{
Salimov $\mathbf{Y}^{1 *}$ and Nurullaev $\mathbf{A A}^{2}$ \\ ${ }^{1}$ Department of Veterinary Surgery, Pharmacology and Toxicology, Doctor of Veterinary Science, Samarkand Institute \\ of Veterinary Medicine, Samarkand, Uzbekistan \\ ${ }^{2}$ Department of Pharmacology and Toxicology, Candidate of Biological Sciences, Samarkand Institute of Veterinary \\ Medicine, Samarkand, Uzbekistan
}

"Corresponding author: Salimov Yunus, Department of Veterinary Surgery, Pharmacology and Toxicology, Doctor of Veterinary Science, Samarkand Institute of Veterinary Medicine, Samarkand, Uzbekistan. E-mail: salimov.yunus61@, mail.ru

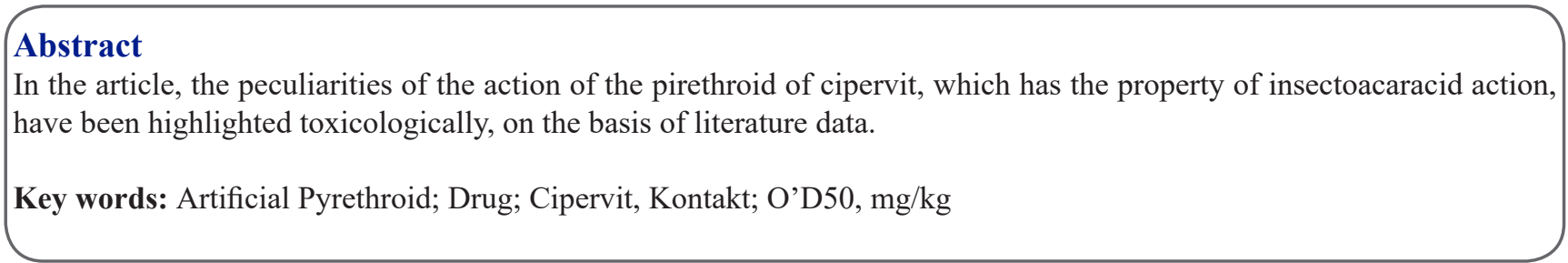

Artificial pyrethroids form the basis of preparations used in agriculture against plant pests and disease-spreading insects and ticks in veterinary practice. One of the representatives of this group is the drug cipervit.

\section{Toxicology}

The drug Cypervitvit is registered mainly as a dezinfection agent, which is used against pests. The drug has insecticide and acaracid effects, has a long and wide spectrum of action on canes and insect predators as well as pests. It is less toxic to humans and warm-blooded animals, as it also has an effective effect on disease-causing fungi. The main causative agent is cipermetrin, a drug belonging to the second generation of artificial pyrethroids. Pesticide with an education to the II class on the degree of toxicity. The effect mexanizmida has the property of influencing through contact and intestines [1]. The drug is applied in the form of aqueous solutions, against scaly, humus, fleas, lice, Pasha, mites and other similar joints. When cipervit is applied, it is absorbed into the body through the outer shell of pests, nerve impulses disrupt the conduction process and lead to death, causing paralysis in insects and Canas. For different animals and poultry, the average lethal dose of cypervitvitnig (O'D50) is from $180 \mathrm{mg} / \mathrm{kg}$ to $200 \mathrm{mg} / \mathrm{kg}$ Gach. Highly toxic drug for bees and fish.

\section{Causes of Poisoning}

In practice, it occurs as a result of poisoning of agricultural animals and poultry from the cipervit, falling into the water basin with a concentration of animal food. Because when these cases arise from a gross violation of the requirements specified for the storage, transportation and use of this drug, as well as from the use of the drug in high quantities, repeated use for a short period of time, as well as from the violation of the expiration dates after processing of food crops (that is, feeding animals in these places), Clinical signs of poisoning. The main clinical signs of utkir lesions of animals and poultry from cypervitvit occur with a violation of the Central and vegetative nervous system. In the organism of injured animals there are cases of general malaise, loss of appetite, a large amount of salivary outflow from the mouth, spasm of the bronchi, a strong spasm of the mucosa and intestinal motility, a violation of the head of movement, a tremor, paralysis of the legs and coma. Death occurs within 24-48-hours after taking pyrethroid into the body [2]. In the blood of poisoned animals and poultry there is a decrease in the amount of hemoglobin, a decrease in the number of blood-shaped elements, as well as an increase in the amount of metgemoglobin in the blood, a decrease in the activity of acetylcholinesterase ferment in blood up to $38-40 \%$.

\section{Patalogoanatomic Changes}

The main pathologoanatomic changes in the body of animals and poultry that have died from this pyrethroid: a violation of blood circulation in the head brain, as well as acute catarrhal inflammation of mucous membranes of internal organs, thorax and small intestine.

\section{Diagnosis}

All data are summarized based on the collected case, that is, Anamnesis data on pesticides used in the farm, whether the animals were related to this poisonous agent, the results of the blood test obtained, the pathologic changes in the animals that died from poisoning, and also on the data of the chemical toxicological laboratory examination. Also in the diagnosis dress carried out a comparison (differential diagnosis) of the diagnosis of diseases of rabies, aueski, gout and botulism [3]. 


\section{Treatment}

When conducting treatment in animals infected with Cypervitvit, it is necessary to pay attention to the fact that there is a property of a sudden effect on the drug. When poisoning is observed, it is recommended to use the following means. As an antidote, atropine provides a good treatment of concomitant collapse, in the amount of $2-5 \mathrm{mg} / \mathrm{kg}$ between the muscles of the sulphate solution, in the amount of $0.25 \mathrm{ml} / \mathrm{kg}$ between the chromosomes of the vein mining vein, and in the amount of 10 $\mathrm{mg} / \mathrm{kg}$ between the muscles of ascorbic acid [4]. These tools are recommended to be sent to a total of 6mart, with an interval of application of xar for 5 hours, depending on the course of the poisoning. When such tools are used, treatment can be achieved up to $60-66$ percent of the total number of injured animals.

\section{Prevention}

Taking into account the low effectiveness of special therapeutic agents in the poisoning of animals and poultry from ciper- vit, the development of anecdotal and preventive measures to identify the causes of the occurrence of poisoning has a practical significance. One of the main works is the storage of such drugs, transportation and when used in veterinary practice in agricultural concentration, the use of them on the basis of the instructions with which the Shake was made and the establishment of Veterinary Control in places, the basis of prevention of poisoning.

\section{References}

1. Rodin SD. Protecting animals from ticks and insects. Moscow. 1981.

2. Klisenko MA. Methods for determining macro-quantities of pesticides. Moscow, Meditsina. 1984.

3. Galutdinova GG, Abulkhanova GM, Tremasov M, Ya Zimakov Yu. A. Toxicological aspects of the use of synthetic pyrethroids in agriculture. Veterinary medicine. 2005;5:51-56.

4. Yuldashev ZA, Popkov VA. Chemical Toxicological studies of synthetic pyrethroids. Moscow University press. 2006;35152. 